\title{
Perancangan dan Implementasi Sistem Pendukung Keputusan Penilaian Pegawai Lapangan Terbaik Pada Pelayaran PT ONI Palembang Menggunakan Metode SAW
}

\author{
Design And Implementation Of The Best Field Employee Assessment Decision Support
} System At Pelayaran PT Oni Palembang Using The SAW Method

\author{
Siti Annisa Dwi Pratiwi ${ }^{1}$, Mardiani ${ }^{2}$ \\ ${ }^{1,2,3}$ Program Studi Sistem Informasi, STMIK GI MDP, Palembang \\ E-mail: ${ }^{1}$ s.annisa.dp24@gmail.com, ${ }^{2}$ mardiani@mdp.ac.id
}

\begin{abstract}
Abstrak
Pelayaran PT. ONI Palembang adalah perusahaan yang bergerak di bidang pelayaran khusus angkutan. Sebagai salah satu perusahaan pelayaran tertua Pelayaran PT. ONI Palembang telah memiliki banyak pegawai kurang lebih 150 pegawai. Perusahaan ini belum menerapkan penilaian pegawai secara sistematis yang menyebabkan tidak optimal nya penilaian terhadap pegawai untuk penilaian pegawai lapangan terbaik. Adapun permasalahan yang ada seperti dokumen hasil penilaian sering hilang sehingga di lakukan penilaian ulang, kriteria penilaian tidak sesuai dan tepat sehingga penulis menggunakan metode Simple Addictive Weighting (SAW) dalam perhitungannya untuk membangun sistem. dalam pembuatan sistem metode pengembangan sistem menggunakan metode RUP dan bahasa pemrograman PHP dan MySQL. Dengan dibuatkan sistem keputusan hasil dari proses ini dapat memberikan suatu alternatif atau solusi keputusan untuk memudahkan menentukan pegawai mana yang akan menjadi pegawai lapangan terbaik yang akan mendapatkan reward atau Bonus.
\end{abstract}

Kata kunci: Sistem pendukung keputusan, Simple Addictive Weighting (SAW), RUP, PHP, $M y S Q L$

\begin{abstract}
Pelayaran PT. ONI Palembang is a company engaged in shipping specifically for transportation. As one of the oldest shipping companies, Pelayaran PT. ONI Palembang already has around 150 employees. This company has not implemented a systematic employee appraisal which has resulted in an inoptimal employee assessment for the best field employee assessment. The existing problems, such as the documents of the assessment results are often lost so that the reassessment is carried out, the assessment criteria are not appropriate and appropriate, so the author uses the Simple Addictive Weighting (SAW) method in his calculations to build the system. In making the system, the system development method uses the RUP method and the programming language PHP and MySQL. By making a decision system the results of this process can provide an alternative or decision solution to make it easier to determine which employee will be the best field employee who will get a reward or bonus.
\end{abstract}

Keywords: Decision support system, Simple Addictive Weighting (SAW), RUP, PHP, MySQL

\section{PENDAHULUAN}

Kemajuan teknologi informasi dan sistem informasi di era globalisasi saat ini sangat pesat, perusahaan di tuntut untuk memiliki manajemen yang handal untuk meningkatkan produktivitas di dalam perusahaan. Kemajuan teknologi juga dapat digunakan oleh manajemen 
dalam memacu proses perkembangan perusahaan sehingga dapat mencapai tujuan perusahaan. Secara umum, teknologi informasi adalah proses perancangan dan implementasi untuk mengolah data dan menghasilkan informasi yang berkualitas dalam membuat, mengubah, menyimpan, mengomunikasikan dan menyebarkan informasi dengan menggunakan seperangkat komputer untuk menjalankannya. Sedangkan sistem informasi adalah suatu sistem yang memberikan informasi untuk mengambil keputusan dan membantu memudahkan dalam proses bisnis perusahaan bahkan hampir semua perusahaan membutuhkan sistem informasi. Perusahaan yang memiliki pegawai yang banyak, harus mempunyai sistem informasi seperti mengelola semua data pegawai agar data yang dihasilkan dapat ter dokumentasi dengan jelas dan mendapatkan informasi berdasarkan kebutuhan bisnisnya.

Dalam proses melakukan penilaian pegawai memang tidak mudah, karena keputusan yang salah dapat berdampak negatif bagi perusahaan, sehingga sistem yang dapat membantu perusahaan mengambil keputusan adalah Sistem Pendukung Keputusan (SPK). DSS adalah Program aplikasi berbasis komputerisasi yang digunakan untuk membantu membuat keputusan yang lebih akurat berdasarkan kriteria yang telah ditentukan sebelumnya. Di dalam sebuah sistem pendukung keputusan terdapat alternatif, kriteria dan bobot untuk menentukan suatu solusi terbaik, dan penggunaan sistem pendukung keputusan dapat membuat keputusan menjadi lebih mudah, cepat, dan akurat.

Pelayaran PT.ONI Palembang merupakan perusahaan bergerak di bidang pelayaran khusus angkutan. Yang berlokasikan di Jalan Sultan Agung No. 543, 1 ilir Palembang. Pelayaran PT.ONI Palembang didirikan pada tahun 1962 dan pada tanggal 2 Juni 1976 mendapatkan pengesahan dari Menteri Kehakiman. Sebagai salah satu perusahaan pelayaran tertua di Palembang, Pelayaran PT. ONI Palembang telah memiliki banyak pegawai apalagi pegawai lapangan yang berjumlah kurang lebih 150 pegawai diantaranya ada beberapa jabatan seperti Nakhoda, Mualim, KKM (Kepala Kamar Mesin), Masinis, Juru Mudi, Juru Minyak, Juru Masak (Koki), Juragan, wakil juragan, Kelasi. Memiliki pegawai yang banyak tentunya Pelayaran PT. ONI Palembang menerapkan penilaian pegawai yang di lakukan oleh staf HRD yang pada saat ini penilaian berdasarkan kriteria yang sama seperti kerjasama tim, lama waktu berlayar dan kedisiplinan. untuk meningkatkan semangat para pegawai tetapi Pelayaran PT.ONI Palembang belum menerapkan penilaian pegawai secara sistematis yang menyebabkan belum optimal nya penilaian terhadap pegawai .Hal ini terjadi karena beberapa permasalahan yang ada di Pelayaran PT. ONI Palembang seperti dokumen hasil penilaian pegawai lapangan sering hilang sehingga membutuhkan waktu untuk melakukan penilaian ulang pegawai lapangan terbaik, kriteria penilaian yang tidak sesuai dan tepat sehingga terjadi kekeliruan dan juga tidak adanya transparan dalam proses penilaian pegawai terbaik dan belum adanya metode perhitungan untuk merekomendasikan pegawai lapangan terbaik. Oleh karena itu untuk memacu semangat pegawai meningkatkan operasional dan kinerjanya di perusahaan Pelayaran PT. ONI Palembang sehingga menjadi lebih baik, Kualitas pegawai juga termasuk faktor penentu keberhasilan suatu perusahaan dan untuk meningkatkan produktivitas kinerja di Pelayaran PT. ONI Palembang diperlukannya manajemen sumber daya manusia untuk penilaian pegawai lapangan terbaik.

Berdasarkan dengan adanya permasalahan diatas, maka penulis akan mencari solusinya dengan membangun sistem pendukung keputusan menggunakan metode Simple Addictive Weighting (SAW) dimana metode SAW dapat menentukan nilai bobot untuk setiap atribut, kemudian dilanjutkan dengan proses perangkingan yang akan menyeleksi alternatif terbaik dari sejumlah alternatif, Penilaian akan lebih tepat karena didasarkan pada nilai kriteria dan bobot yang sudah di tentukan, dan adanya perhitungan ter normalisasi matriks sesuai dengan atribut (benefit dan cost). Maka penulis akan memberi judul penelitian "Perancangan dan Implementasi Sistem Pendukung Keputusan Penilaian Pegawai Lapangan Terbaik pada Pelayaran PT. ONI Palembang Menggunakan Metode SAW". Dan hasilnya dapat memberikan solusi untuk memudahkan penilaian pegawai mana yang akan menjadi pegawai lapangan terbaik yang akan mendapatkan reward/ Bonus. 


\subsection{Sistem}

Sistem adalah sekumpulan prosedur yang saling berkaitan dan saling terhubung untuk melakukan suatu tugas bersama-sama [1].

\subsection{Informasi}

Informasi adalah data yang telah diolah sehingga pengetahuan dari orang yang menggunakan data mengalami peningkatan [2].

\subsection{Keputusan}

Keputusan merupakan hasil dari proses memilih pilihan terbaik diantara beberapa alternatif yang telah tersedia. Pada proses pengambilan keputusan kita akan berusaha mencurahkan segala pemikiran dan melakukan kegiatan yang diperlukan untuk mendapatkan pilihan terbaik Kegiatan yang telah tersedia [3].

\subsection{Sistem Pendukung Keputusan}

Sistem Pendukung Keputusan adalah suatu sistem informasi spesifik yang mengatur untuk membantu manajemen dalam mengambil keputusan yang berkaitan dengan masalah yang bersifat semi terstruktur [4].

\subsection{Metode Simple Additive Weighting (SAW)}

Metode Simple Additive Weighting (SAW) adalah metode penjumlahan bobot dari kinerja setiap objek-objek yang berbeda dan memiliki kesempatan yang sama pada semua kriteria yang dimiliki [5].

$$
r_{i j}= \begin{cases}\frac{X_{i j}}{\operatorname{Max}_{i} X_{i j}} \rightarrow & \text { Jika } j \text { adalah attribute keuntungan } \\ \text { (benefit) }\end{cases}
$$

Keterangan:

rij $\quad=$ nilai rating kinerja ternormalisasi

xij = nilai atribut yang dimiliki dari setiap kriteria

Maxi xij = nilai terbesar dari setiap kriteria $\mathrm{i}$

Mini $x i j=$ nilai terkecil dari setiap kriteria $\mathrm{i}$

benefit $=$ jika nilai terbesar adalah terbaik

cost = jika nilai terkecil adalah terbaik

dimana rij adalah rating kinerja ternormalisasi dari alternatif $\mathrm{Ai}$ pada atribut $\mathrm{Cj}$; $\mathrm{i}=1,2, \ldots, \mathrm{m}$ dan $\mathrm{j}=1,2, \ldots, \mathrm{n}$. Nilai preferensi untuk setiap alternatif (Vi) diberikan sebagai:

$$
\mathrm{V}_{\mathrm{i}}=\sum_{\mathrm{j}=1}^{\mathrm{n}} \mathrm{w}_{\mathrm{j}} \mathrm{r}_{\mathrm{ij}}
$$

Keterangan:

$\mathrm{Vi} \quad=$ rangking untuk setiap alternatif

$\mathrm{Wj} \quad=$ nilai bobot dari setiap kriteria

rij = nilai rating kinerja ternormalisasi

Nilai Vi yang lebih besar mengindikasikan bahwa alternatif Ai lebih terpilih. Langkah 
penyelesaian metode Simple Additive Weighting (SAW), diantaranya:

- Memberikan nilai setiap alternatif (Ai), pada setiap kriteria $(\mathrm{Cj})$ yang sudah ditentukan dimana nilai $i=1,2, \ldots, m$ dan $j=1,2, \ldots, n$.

- Memberikan nilai bobot (W) yang juga didapatkan berdasarkan nilai keanggotaan.

- Melakukan normalisasi matriks dengan cara menghitung nilai rating kinerja normalisasi dari alternatif $\mathrm{Ai}$, pada atribut $\mathrm{Cj}$ berdasarkan persamaan yang disesuaikan dengan jenis atribut (atribut keuntungan $/$ benefit $=$ MAKSIMUM atau atribut biaya $/ \operatorname{cost}=$ MINIMUM). Apabila berupa atribut dibagi dengan nilai keanggotaan MAX (MAX Xij) dari tiap kolom sedangkan untuk atribut biaya. Nilai keanggotaan MIN (MIX Xij) dari tiap kolom atribut dibagi dengan nilai kenggotaan (Xij) setiap kolom.

- Melakukan proses perangkingan untuk setiap alternatif (Vi) dengan cara mengkalikan nilai bobot $(\mathrm{Wj})$ dengan nilai rating kinerja ternormalisasi (rij).

\subsection{PHP}

Hypertext Preprocessor atau lebih akrab dengan sapaan PHP merupakan bahasa pemrograman script server-side yang di-desain untuk pengembangan web. PHP disebut bahasa pemrograman server-side karena diproses pada komputer server [6].

\subsection{My SQL}

MySQL adalah software Relational Database Management System (RDBMS) opensource yang paling populer digunakan untuk menyimpan data dari aplikasi berbasis web [7].

\subsection{Metode Rational Unified Process (RUP)}

RUP (Rational Unified Process) adalah pendekatan pengembangan perangkat lunak yang dilakukan berulang-ulang (iterative), pada arsitektur architecture-centric), lebih diarahkan berdasarkan pengguna kasus (use case driven). RUP merupakan proses rekayasa perangkat lunak dengan pendefinisian yang baik (well defined) dan penstrukturan yang baik (well structured) [8].

\section{METODE PENELITIAN}

\subsection{Teknik Pengumpulan Data}

Teknik Pengumpulan data pada proposal skripsi ini dilakukan dengan cara sebagai berikut:

a. Wawancara

Penulis melakukan wawancara bersama HRD di Pelayaran PT.ONI Palembang agar dapat mengetahui permasalahan, proses pengambilan keputusan dan mengetahui informasi perusahaan yang berhubungan dengan penilaian pegawai pada Pelayaran PT ONI Palembang. b. Observasi

Penulis melakukan observasi agar penulis dapat mengamati tentang bagaimana proses penilaian pegawai terbaik yang berhubungan dengan pembuatan sistem pendukung keputusan di Pelayaran PT ONI Palembang.

c. Studi Pustaka

Penulis melakukan pengumpulan beberapa artikel, jurnal serta buku-buku yang ada di perpustakaan yang menjadi sumber dari penelitian terdahulu yang berhubungan dengan permasalahan tema skripsi yaitu SPK sebagai pedoman penulis untuk memperkuat argumentasi penelitian.

\subsection{Metodologi Pengembangan Sistem}

Metodologi Pengembangan Sistem yang digunakan penulis dalam melaksanakan penelitian adalah metode RUP (Rational Unified Process). Metode RUP memiliki 4 Fase yaitu 
sebagai berikut:

1. Fase inception (permulaan)

Fase ini penulis memahami terlebih dahulu pemodelan bisnis yang di butuhkan (business modelling) dan kebutuhan sistem yang akan di buat meliputi tahapan- tahapan seperti wawancara, observasi, dan studi pustaka.

2. Fase Elaboration (Perluasan/ Perencanaan)

Fase ini penulis melakukan perencanaan untuk mendeteksi mengurangi resiko yang akan terjadi. Pada tahap ini penulis membuat perancangan Use case, membuat Analisis PIECES, membuat Activity diagram untuk menggambarkan aliran kerja dari sebuah sistem, Membuat class diagram, Membuat sequence diagram serta penulis akan merancang layout website yang akan dibuat.

\section{Fase Construction (konstruksi)}

Fase ini penulis melakukan pembuatan database dan website dan interface sistem. Fase ini juga melakukan pengujian website yang telah dibangun untuk memperbaiki kesalahan jika masih ada yang belum sesuai dengan yang diharapkan user dan mudah dipakai serta mudah dimengerti.

\section{Fase Transitional (transisi)}

Fase ini dilakukan tahapan untuk menyerahkan sistem kepada pengguna (user). Tahap ini termasuk memberikan pelatihan dan pengujian sistem agar mengetahui apakah sistem tersebut sudah memenuhi harapan user.

\section{HASIL DAN PEMBAHASAN}

\subsection{Analisis Permasalahan}

Adapun permasalahan di Pelayaran PT. ONI Palembang yang akan di identifikasikan dengan menggunakan kerangka PIECES.

Tabel 1. PIECES

\begin{tabular}{|l|l|}
\hline PIECES & Keterangan \\
\hline $\begin{array}{l}\text { Performance } \\
\text { (perfoma) }\end{array}$ & $\begin{array}{l}\text { Membutuhkan waktu yang lama kurang lebih sekitar 1 bulan saat } \\
\text { melakukan penilaian karena dokumen hasil penilaian sering hilang } \\
\text { sehingga harus dilakukan penilaian ulang. }\end{array}$ \\
\hline $\begin{array}{l}\text { Information } \\
\text { (Informasi) }\end{array}$ & $\begin{array}{l}\text { Informasi dari hasil penilaian yang hilang mengakibatkan tidak ada } \\
\text { riwayat penilaian pegawai lapangan terbaik, sehingga data penilaian yg } \\
\text { dihasilkan tidak dapat ter dokumentasi dengan jelas. }\end{array}$ \\
\hline $\begin{array}{l}\text { Economic } \\
\text { (Ekonomi) }\end{array}$ & $\begin{array}{l}\text { - Kesalahan dalam penilaian pegawai dapat menimbulkan kerugian yaitu } \\
\text { baik dari segi waktu maupun dari segi pengeluaran biaya yang } \\
\text { memakan banyak kertas yang dapat mencapai Rp. 500.000 }\end{array}$ \\
\hline $\begin{array}{l}\text { Control } \\
\text { (Pengendalian) }\end{array}$ & $\begin{array}{l}\text { Terjadi kekeliruan dalam penilaian pegawai lapangan terbaik karena } \\
\text { kriteria penilaian yang tidak sesuai dan tepat. }\end{array}$ \\
\hline $\begin{array}{l}\text { Efficiency } \\
\text { (efisien) }\end{array}$ & $\begin{array}{l}\text { - Heterbukaan cara penilaian pemilihan pegawai terbaik. } \\
\text { jumlah pegawan perhatungan penilaian secara berulang sesuai dengan } \\
\text { - Sering terjadi kesalahan dalam penilaian karena metode perhitungan } \\
\text { tidak jelas sehingga perusahaan melakukan perhitungan secara ulang. }\end{array}$ \\
\hline $\begin{array}{l}\text { Service } \\
\text { (Layanan) }\end{array}$ & $\begin{array}{l}\text { Adanya pegawai lain yang seharusnya mendapatkan penilaian pegawai } \\
\text { lapangan terbaik tetapi tidak terpilih karena adanya kesalahan, sehingga } \\
\text { pegawai lain tersebut merasa kurang puas. }\end{array}$ \\
\hline
\end{tabular}




\subsection{Analisis Kebutuhan Fungsional}

Analisis kebutuhan fungsional adalah salah satu analisis yang digunakan untuk menggambarkan perilaku user sistem dan memberikan gambaran umum sistem yang akan dibangun, Use Case diagram dapat memudahkan dalam memahami perilaku sistem yang digambarkan sebagai Actor sistem Use Case Diagram yang diusulkan pada Perusahaan Pelayaran PT. ONI Palembang memiliki 3 Aktor.

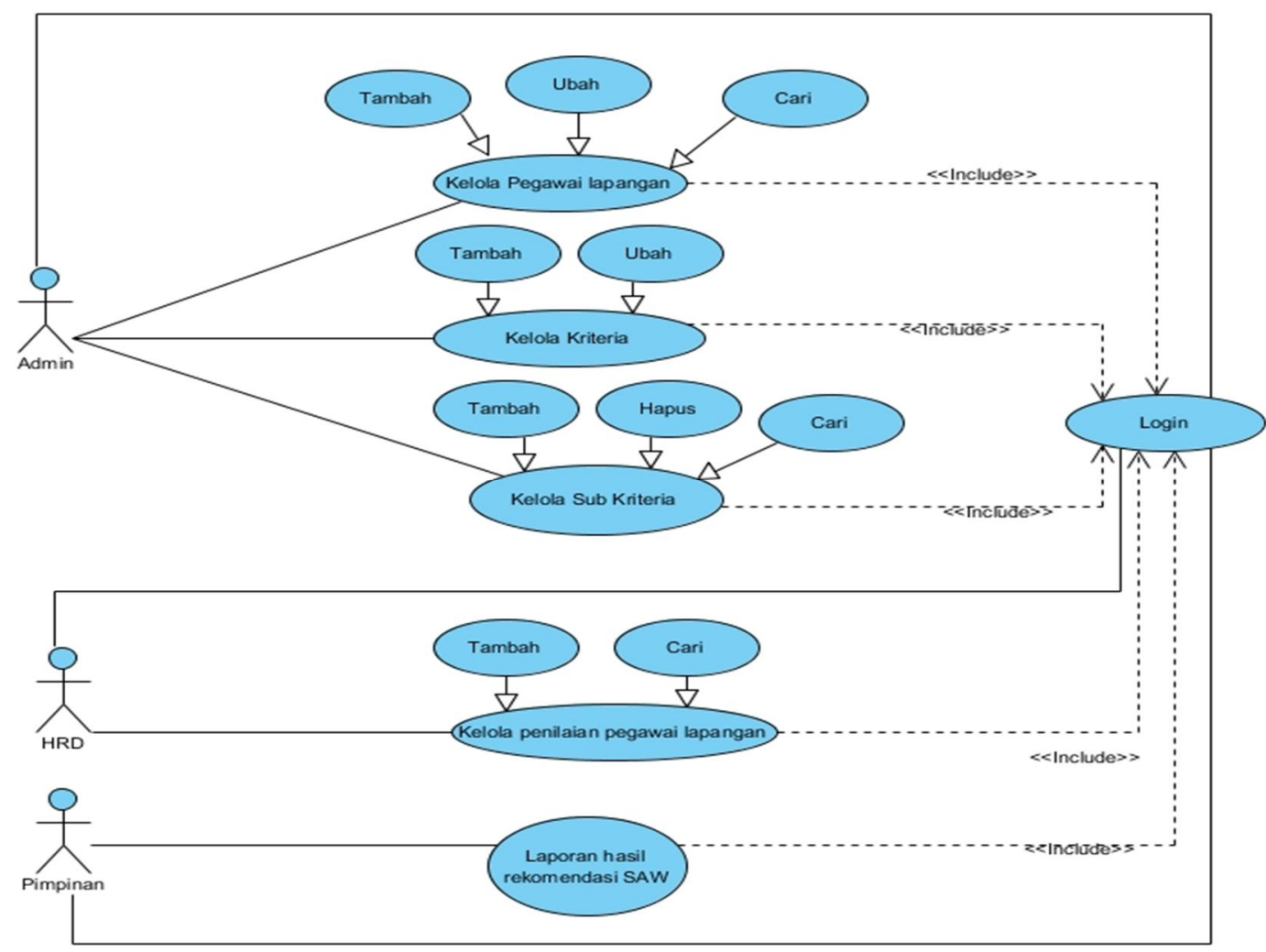

Gambar 1. Use Case Diagram

\subsection{Rancangan sistem}

Rancangan sistem dibuat menggunakan Activity diagram, Class diagram, Sequence diagram, dan tampilan antarmuka sistem.

\subsubsection{Activity Diagram}

Activity diagram menggunakan workflow (aliran kerja) atau aktivitas dari sebuah sistem atau proses bisnis atau menu yang ada pada perangkat lunak, yang perlu diperhatikan disini adalah bahwa diagram aktivitas menggambarkan aktivitas sistem bukan apa yang dilakukan aktor, jadi aktivitas yang dapat dilakukan oleh sistem. Berikut Activity diagram ini menggambarkan proses aliran data masuk dan keluar pada saat melakukan tambah pegawai. 


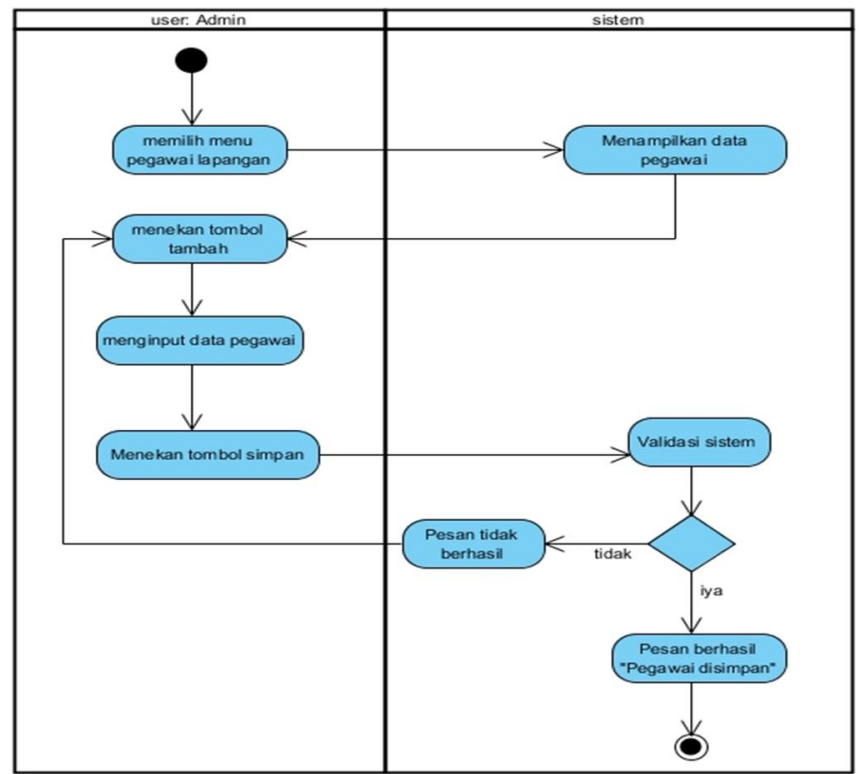

Gambar 2. Activity Diagram Tambah Pegawai

\subsubsection{Class Diagram}

Diagram kelas atau class diagram menggambarkan struktur sistem dari segi pendefinisian kelas-kelas yang akan dibuat untuk membangun sistem. Kelas memiliki apa yang disebut atribut dan metode atau operasi.

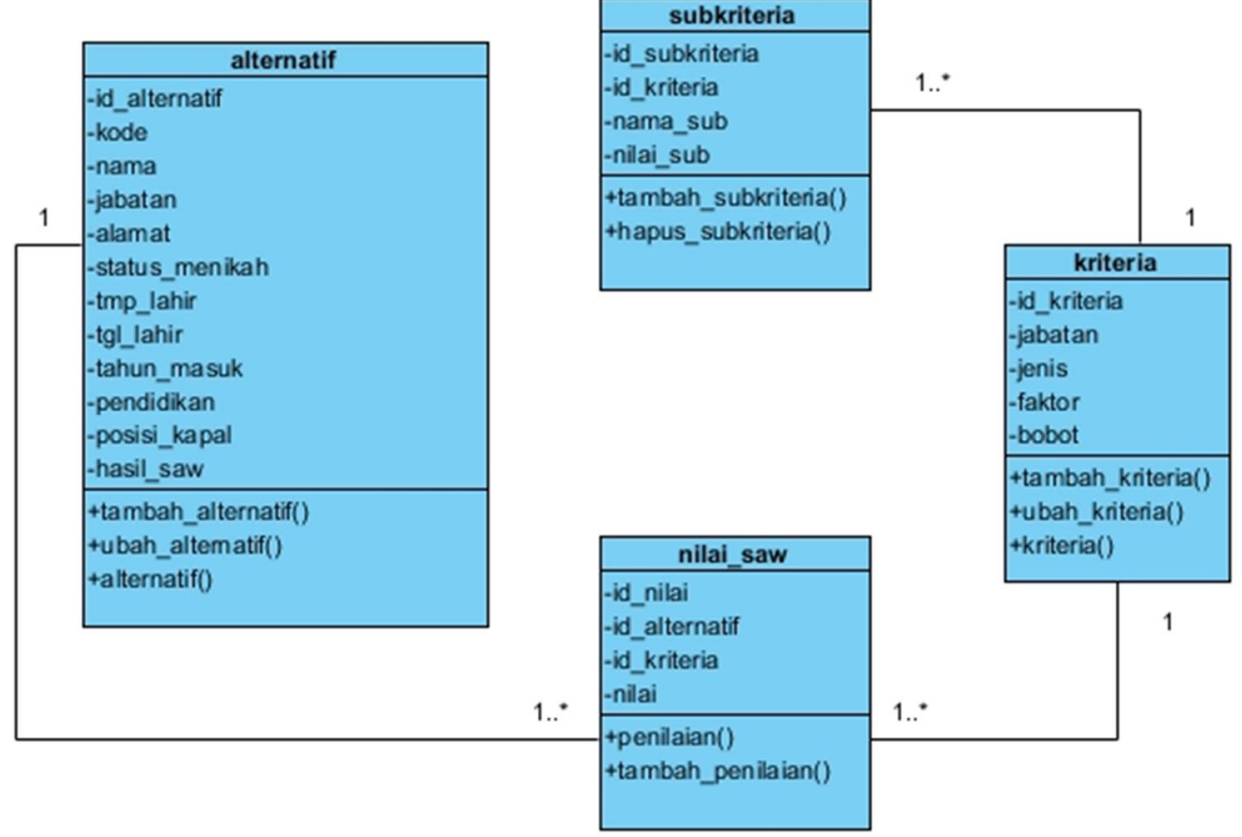

Gambar 3. Class Diagram

\subsubsection{Sequence Diagram}

Sequence Diagram menggambarkan kelakuan objek pada use case dengan mendeskripsikan waktu hidup objek dan message yang dikirimkan dan diterima antar objek. Berikut Sequence diagram yang menggambarkan user saat melakukan proses penambahan data pegawai 


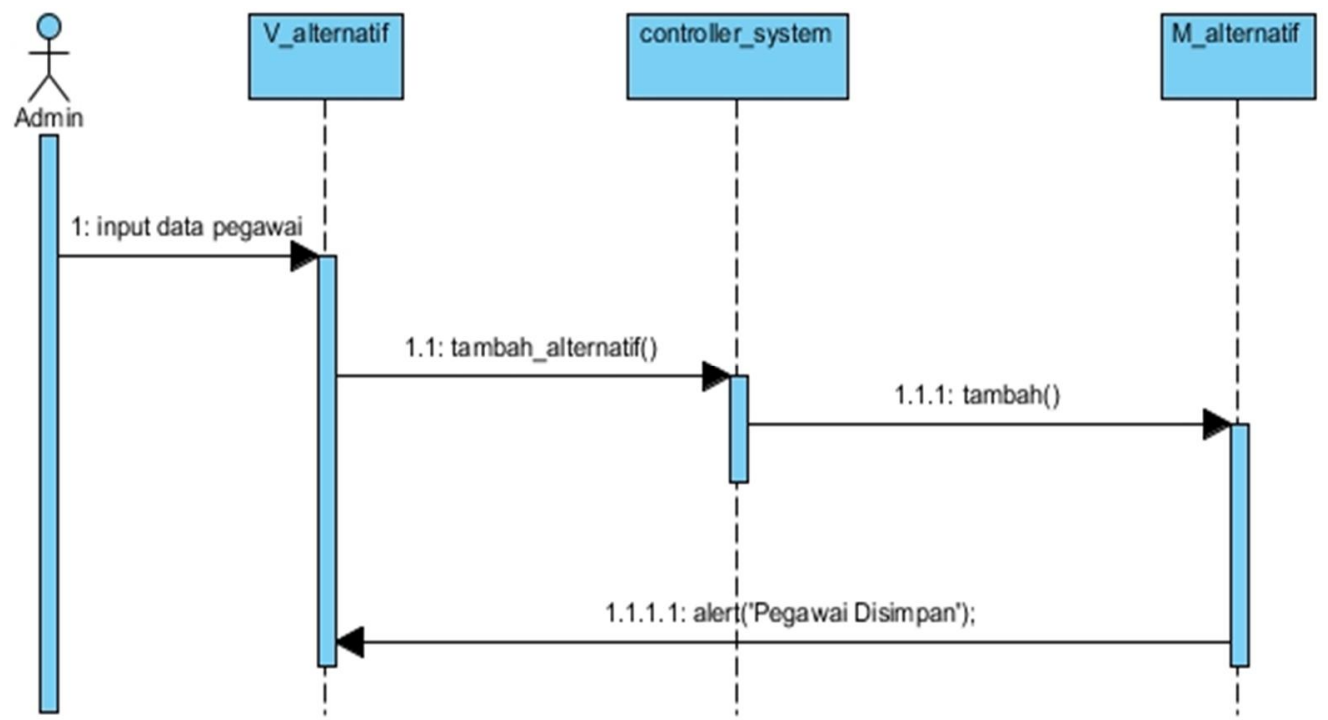

Gambar 4. Sequence Diagram Tambah Pegawai

\subsubsection{Tampilan Antarmuka Sistem}

Tampilan menu beranda admin, HRD, Pimpinan berisikan visi misi perusahaan dan pada user Admin menu pegawai lapangan dan kriteria, Tampilan menu beranda HRD berisikan menu penilaian pegawai lapangan. Tampilan menu beranda Pimpinan berisikan menu Laporan hasil rekomendasi $S A W$.

\section{Pelayaran PT ONI}

Pegawai Lapangan

Tampil Data Pegawai Lapangan

Show $10 \vee$ entries

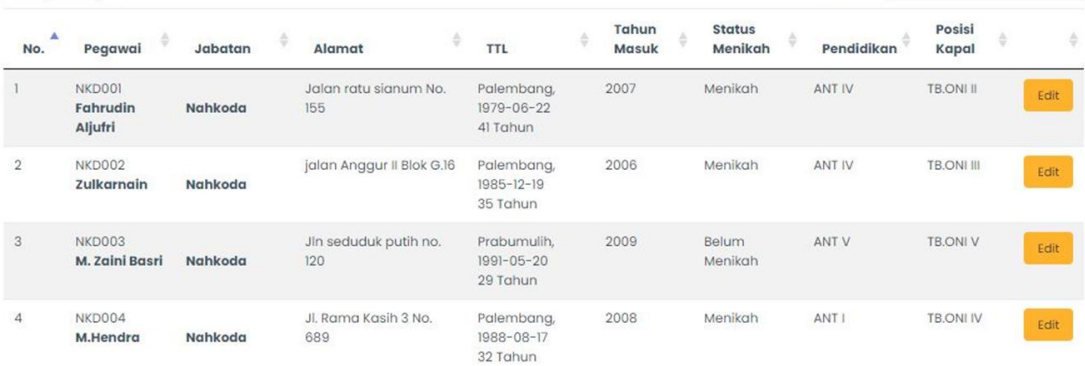

Gambar 5. Antarmuka Kelola Pegawai Lapangan 


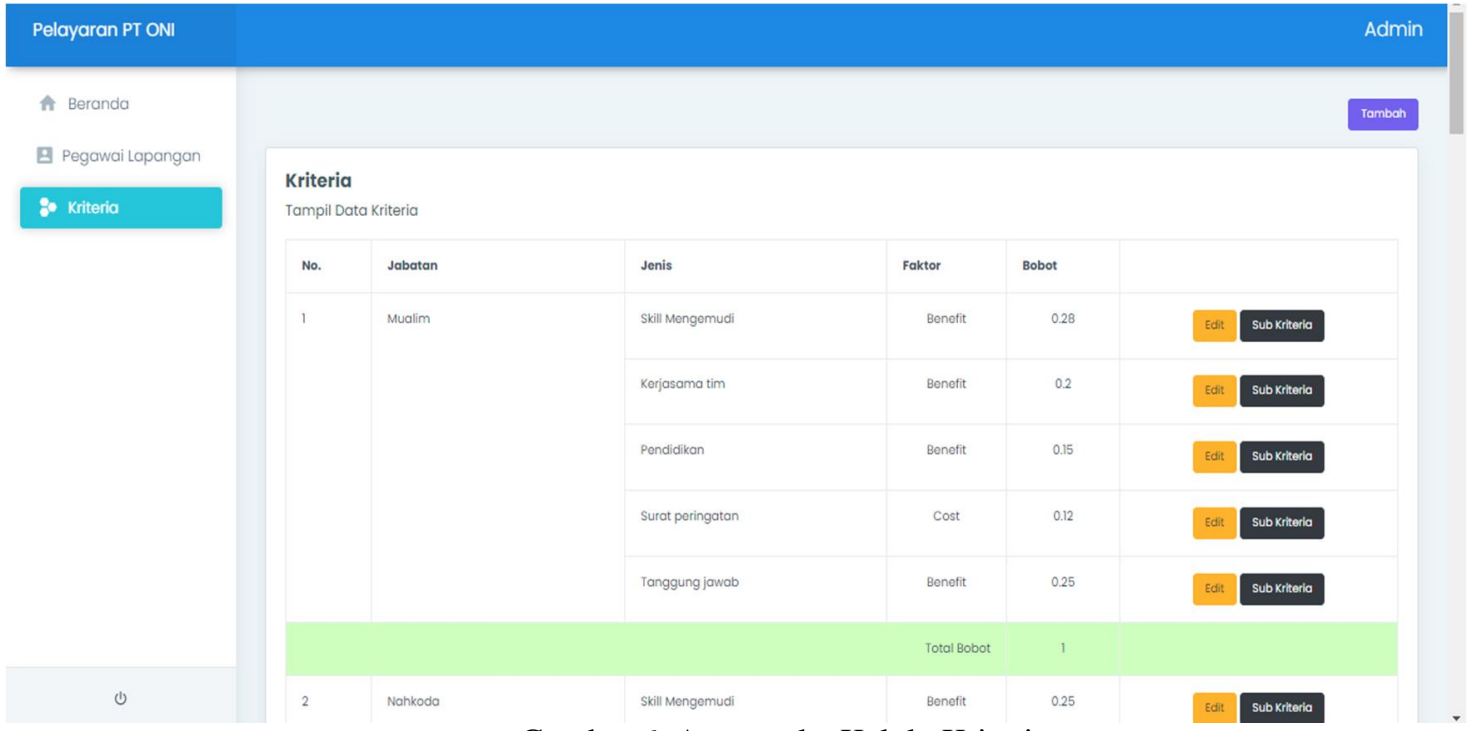

Gambar 6. Antarmuka Kelola Kriteria

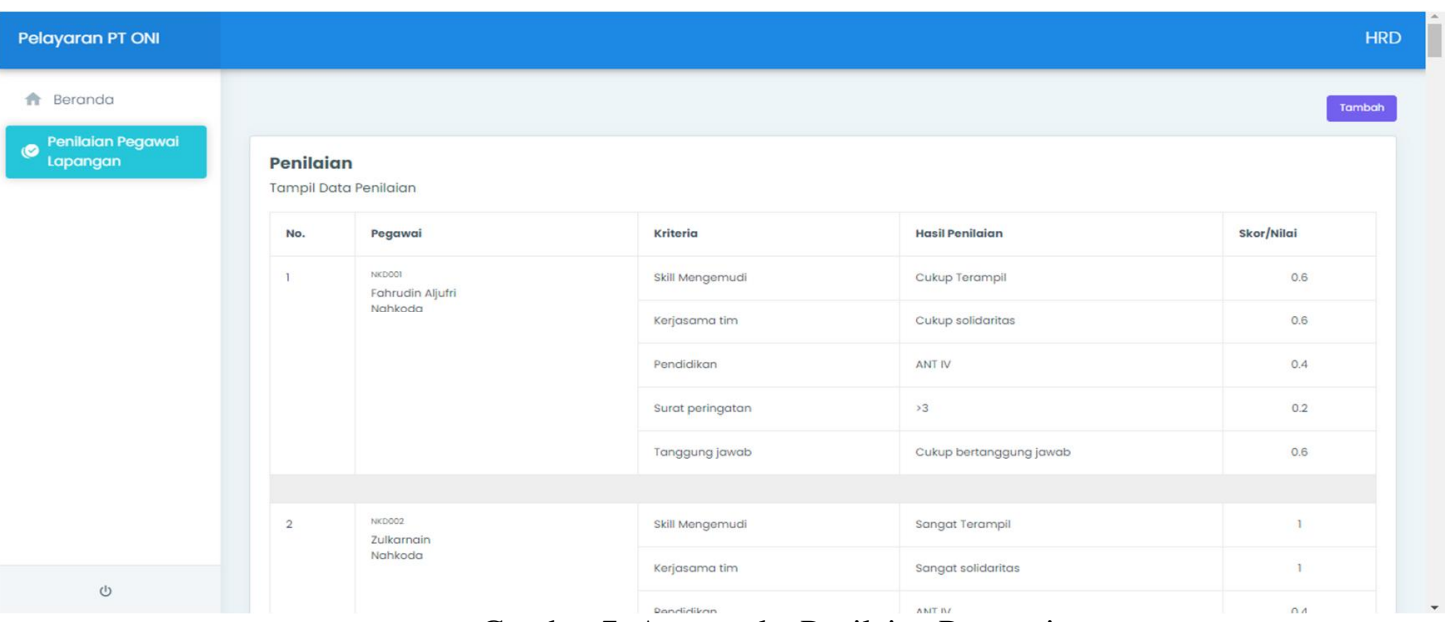

Gambar 7. Antarmuka Penilaian Pegawai

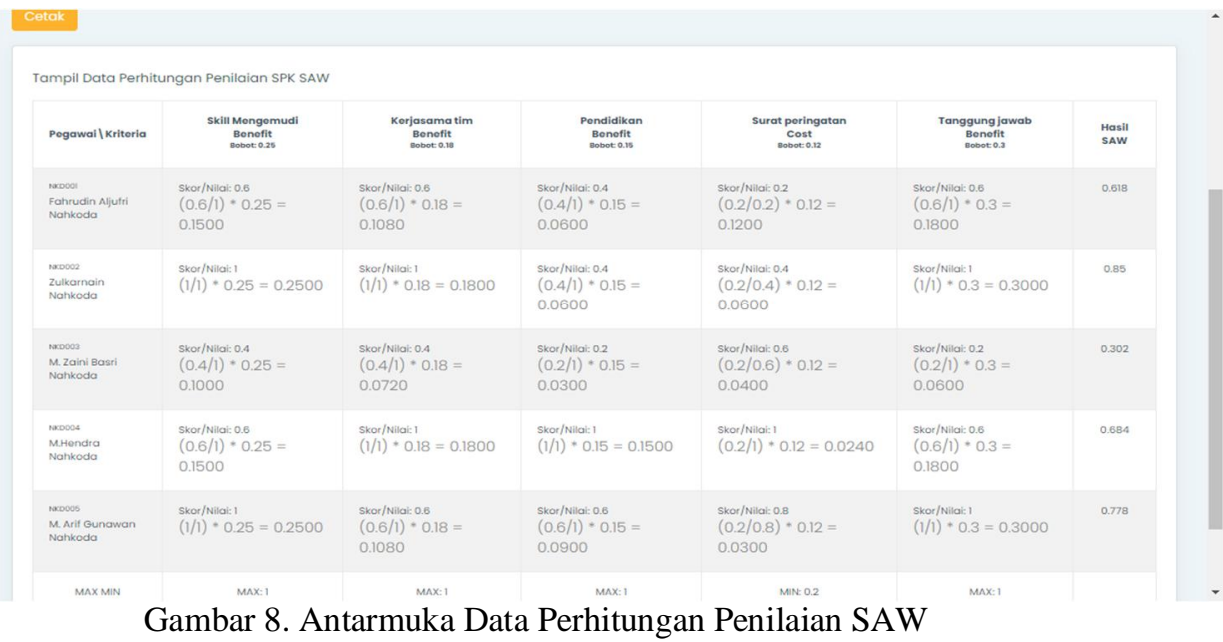




\section{KESIMPULAN DAN SARAN}

\subsection{Kesimpulan}

Berdasarkan dari pembahasan dan uraian penelitian yang berjudul "Perancangan dan Implementasi Sistem Pendukung Keputusan Penilaian Pegawai Lapangan Terbaik pada Pelayaran PT.ONI Palembang menggunakan metode SAW", maka penulis dapat mengambil kesimpulan sebagai berikut:

- Faktor penilaian sistem pendukung keputusan pegawai lapangan terbaik pada Pelayaran PT.ONI Palembang sudah ditetapkan kriteria nya oleh HRD berdasarkan masing-masing jabatannya.

- Sistem Pendukung keputusan ini dirancang agar dapat memudahkan perusahaan dalam melakukan penilaian pegawai lapangan terbaik pada Pelayaran PT. ONI Palembang dengan ditentukan pengelompokan terhadap kriteria berdasarkan sangat baik, baik, kurang baik, cukup baik dan tidak baik, dimana kriteria yang dianggap sangat baik dihitung nilainya sebagai 1 , kriteria yang dianggap baik nilainya dihitung 0,80 , kriteria yang dianggap cukup baik nilainya dihitung 0,60 , kriteria yang dianggap kurang baik nilainya dihitung 0,40 , sedangkan kriteria yang dianggap tidak baik nilainya dihitung 0,20.

- Sistem pendukung keputusan ini dapat menampilkan hasil rekomendasi pegawai lapangan terbaik dengan menggunakan metode SAW.

\subsection{Saran}

Berdasarkan dari proses hasil analisa pembuatan penelitian yang sudah dilaksanakan maka ada beberapa saran yang ingin penulis sampaikan sebagai berikut:

- Sistem pendukung keputusan yang dibangun perlu dilakukannya pemeliharaan dan peningkatan sistem secara berkala.

- Sistem pendukung keputusan yang telah di bangun, sebaiknya digunakan dan dimanfaatkan sebagai mana fungsinya yaitu untuk membantu proses penilaian pegawai.

- Sebaiknya agar selalu melakukan back up karena banyaknya data penting yang tersimpan di database.

\section{DAFTAR PUSTAKA}

[1] E, P, I Putu Agus. 2014, Sistem Informasi dan Implementasi, Informatika, Bandung.

[2] Reksoatmodjo, Wahyuni. 2018, Analisis dan Perancangan Sistem Basis Data, Andi, Yogyakarta.

[3] Diana. 2018, Metode dan Aplikasi Sistem Pendukung Keputusan. Deepublish: Yogyakarta

[4] Nofriansyah, Dicky \& Defit, Sarjon. 2017, Multi Criteria Decision Making (MCDM) pada Sistem Pendukung Keputusan. Deepublish: Yogyakarta

[5] Pratiwi, Heny. 2016, Buku Ajar: Sistem Pendukung Keputusan. Deepublish: Yogyakarta

[6] Miftahul, Sarwandi, dan Cyber Creative. 2019, Mahir Bahasa Pemograman PHP: PT.Elex Media Komputindo, Jakarta.

[7] Raharjo, Budi. 2015, Mudah Belajar PHP. Bandung, Informatika

[8] A.S, Rosa dan M. Shalauddin. 2013, Rekayasa Perangkat Lunak Terstruktur dan Berorientasi Objek, Informatika, Bandung. 